\title{
The catchment area of high architectural railway stations: an application of the Graham scan algorithm
}

\author{
A. Cartenì, G. Galante \& I. Henke \\ Department of Civil, Construction and Environmental Engineering, \\ University of Naples Federico II, Italy
}

\begin{abstract}
Transit services quality has long been recognized as an important factor in influencing travellers' behaviour and a terminal's architectural quality is certainly part of it. As a matter of fact a number of transit promotion policies explicitly based on qualitative factors and specifically high architectural standards are being adopted in designing new railways stations. Several examples of remarkable architecture applied to railways stations can be found all round the world. The aim of this paper is to estimate and compare the "catchment area" of both traditional metro stations and high architectural quality ones, taking advantage of the metro Line 1 in Naples (Italy), also called "Metrò dell'arte" (art in the Metro). This metro line is a high quality line where many international level architects were involved to ensure high aesthetic quality standards for the new stations. The originality of the experiment field is that the rail network including both traditional and new metro lines (and stations) connect homogeneous areas of the city, either for transport system accessibility (same service frequency and same mode/service alternative) and for socio-economic aspects (same population density, income and employment, average age etc.).

Graham's scan algorithm was used to estimate the catchment areas of the Naples metro stations through transportation surveys conducted in 2013. The estimation results show that the "catchment area" of the high quality station is greater than a traditional one, of approximately $99 \%$. These results suggest that high architectural standards for railways stations should be considered as an explicit design variable in transportation planning.
\end{abstract}

Keywords: public transport quality, railways stations, architectural quality impacts, Graham scan algorithm, travellers behaviour. 


\section{Introduction}

In developed countries, public transport (PT) quality plays an important role in travellers' behaviour, becoming one of the main objectives of sustainable transport policies. The quality of public transport services depends on several attributes, some of them are quantitatively measurable (e.g. average travel time and waiting time, regularity of service, monetary costs), others can only be assessed qualitatively (e.g. comfort, information, security).

Moreover, the aesthetic and architectural standards of transport terminals have an important role as well as the quality of the public transport service. In this field, since the eighties, an architectural movement called "Station Renaissance" has spread throughout Europe. This movement, through the upgrading of stations, aims to focus on comfort within travel (e.g. aesthetics and landscapes) and a renewal of the image of rail operators [1]. The "Station Renaissance" is promoted firstly by service operators themselves in order to renovate historic stations. Later the "Station Renaissance" also rapidly spread with the aim of designing new stations and urban redevelopment of cities (for example: Toledo Station on Line 1 in Naples, Vystavochniy Station in Kiev, Victory Park Station in Moscow and Wilhelmina Station in Rotterdam). The main features of this architectural movement to design and upgrade railway stations are [2-5]:

- $\quad$ aesthetics (e.g. use of simple forms, harmony of materials and colors);

- quality of the architecture (e.g. high architectural standards);

- integration with the surrounding landscape (e.g. a pleasant environment and visual impact);

- accessibility and interchange of different transport modes (e.g. with the bus system, car parks and ports and airports).

In the early nineties the "Station Renaissance" migrated from Europe to the United States with the development of the so-called "Context Sensitive Design for Railways" (CSDR). This is a movement based on the awareness of the social and environmental impact that new infrastructures have [6]. So the aesthetic became a central element in the construction of infrastructures for sustainable transport, with the aim of improving the livability of the surrounding areas. The concept of aesthetic is not only limited to a purely visual quality (which is based on the analysis of shapes, size, color and so on) but also includes more subjective aspects such as utility and visual impressions [7].

Thus, despite the many movements mentioned above and the consequent achievements, which have enhanced the aesthetic quality, there is still a limited scientific analysis on the non-quantitative aspects of quality in public transport (such as the aesthetic standards of the railway and underground stations). That had the aim of evaluating the effects of these variables on mobility behaviors. In the literature, in fact, the problem of service quality has been compared with traditional attributes such as regularity, comfort, level of crowding, etc. [4, 8, 9]. Recently Cascetta and Cartenì [10] proposed for the first time in literature a quantitative analysis of the perceived hedonic value of stations for railway travel, as compared to more conventional service variables, such as waiting, on-board 
and access times, service frequency and monetary cost. These authors quantify the value of station quality in 35 Euro cents/trip for students and in 50 Euro cents/trips for commuters.

Starting from this consideration, the aim of this paper is to estimate and compare the "catchment area" of traditional metro stations with high architectural quality ones, taking advantage of the metro Line 1 in Naples (Italy), also called "Metrò dell'arte" (art in the Metro). This metro line is a high quality line $[3,5]$ where many architects at international level were involved to ensure high aesthetic quality standards for the new stations. Recently, the new Toledo Station, one of the Line 1 metro stations, has been defined first by the Daily Telegraph and then later by the $\mathrm{CNN}$ as the most impressive metro station of Europe (Figure 1).

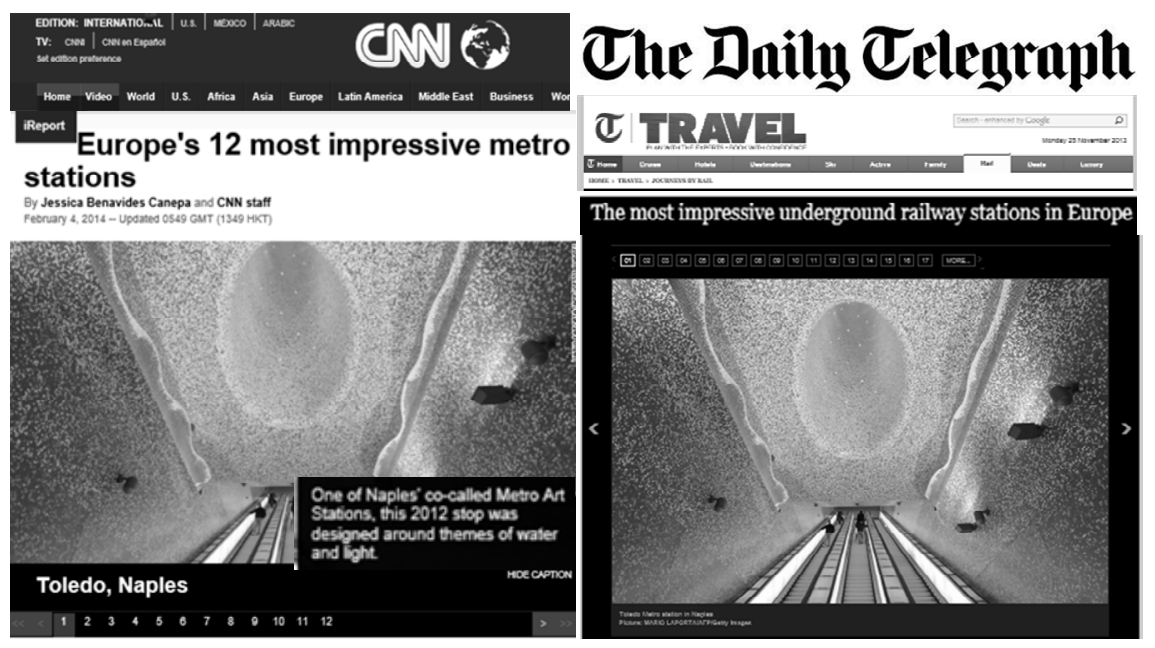

Figure 1: The Toledo metro station, defined as the most impressive station of Europe by prestigious newspapers [11,12].

Furthermore, Graham's scan algorithm [13] was used to estimate the catchment areas (convex envelope) of the Naples metro stations. The Graham scan method is a computational geometric algorithm for finding a two-dimensional convex hull. In this paper we propose a transport application of this method for the estimation of metro station catchment areas.

The paper is organized as follows: Section 2 describes the application case study and survey; Section 3 presents the main results in terms of catchment area estimations. Finally, the conclusions and research perspectives are reported in Section 4.

\section{Case study and survey}

As already stated, the case study is the Naples Underground. Naples is one of the highest population density cities in Europe with about one million people and a 
density of 8,058 people/Kmq. These socio-economics and territorial characteristics make this city particularly suitable for a public transport system based on the railway Transit Oriented Development [5]. For over 20 years, an integrated planning project based on the use of railways has been set out. Today, Naples has 9 urban metropolitan lines and it is considered that by the end of project, $60 \%$ of Neapolitans will have a metro station less than 500 metres away from them.

The most important underground lines in Naples (with regard to population served and moved) are Line 1 and Line 2. Line 1, "Metrò dell'arte" (art in the Metro), is long, about $17 \mathrm{~km}$, has 17 stations with about 110 thousand users per day. Line 2 is the oldest line in Naples, is long, about $15 \mathrm{~km}$, with 11 stations and more than 75 thousand users per day. As already stated, the aim of this paper is to compare the "catchment area" of a traditional station (metro Line 2) with a high architectural one (metro Linea 1), as shown in the examples in Figure 2.

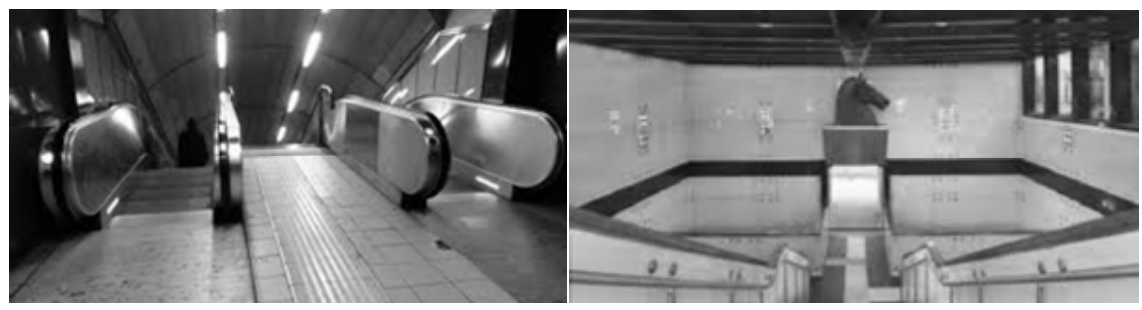

Figure 2: An example of a traditional station (on the left) vs. a high architectural standard one (on the right).

The idea to compare the "catchment area" of the two main underground lines of Naples (Figure 3), Line 1 (high architectural standard) and Line 2 (traditional), has been possible thanks to the fact that these two lines connect homogeneous areas of the city, either for transport system accessibility (same service frequency and same alternative transport way) or for socio-economic aspects (same population density, income and employment, average age, etc.). This particular, and probably unique, condition allowed people to say that the difference between the two catchment areas is due to distinct aesthetic and architectural characteristics of the two stations instead of different functional aspects.

Between October and November 2013 about 6,000 users, coming in and out of the main stations of both lines have been interviewed. They were asked their pedestrian origin/destination address, their gender and purpose of the trip.

The results of the survey confirm the hypothesis that the users of the two services have similar (homogeneous) socio-economic and trip characteristics. It has been observed that $59 \%$ of the users of Line 1 are female, while $55 \%$ have work or study as the purpose of their trip. On the other hand, $58 \%$ of the users of Line 2 are female, while $63 \%$ have work or study as the purpose of their trip.

In addition, the survey results showed a significant difference between the extent of the catchment area of the traditional station and the high architectural standard station. 
For brevity in the following only the results of two of the main stations of Naples' historical centre (characterized by 600 metres distance from each other) are reported (Figure 3): Dante Station for Line 1 (high architectural standards station) and Montesanto Station for Line 2 ("traditional" station). Similar results have been found for all the other stations analysed for the two lines.

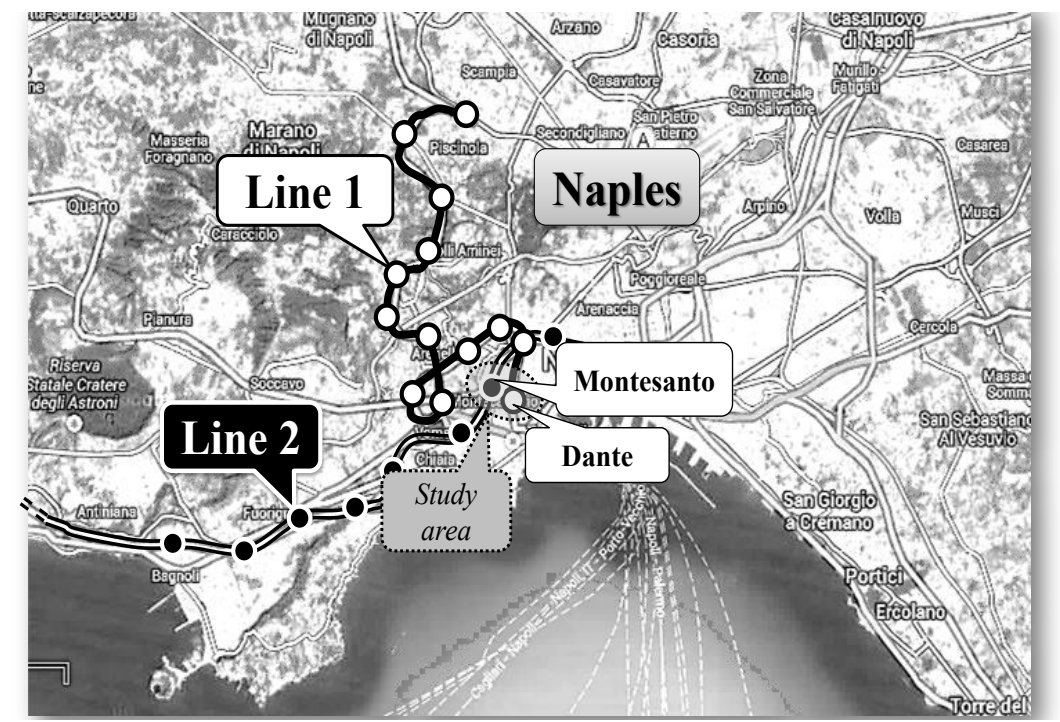

Figure 3: $\quad$ Line 1 and Line 2 of the Naples metro system in December 2013.

\section{Catchment area of railways stations}

As already stated, the Graham's scan method [13] has been used to estimate the catchment areas (convex envelope) of the two Naples metro stations: Dante and Montesanto. Starting from the addresses declared by the 3,071 users interviewed at the two stations (over 6,000 in total for all stations monitored), set $N_{l}=1,510$ interviews at the Dante station and $N_{2}=1,561$ the interviews at the Montesanto station, through GIS software, it was possible to locate the interviewed users' origins/destinations. Through the Graham's scan method the convex envelope (sometimes named convex hull) was estimated for both stations, starting from the two sets of points $N_{1}$ and $N_{2}$. For the Dante convex envelope, the Graham's algorithm finds all vertices of the convex envelope ordered along its boundary. The first step of the algorithm was to find the starting point $S$, characterized by the lowest y-coordinate (if the lowest y-coordinate exists in more than one point, the point with the lowest $\mathrm{x}$-coordinate was the starting one). Next, the other $N_{l^{-}} 1$ points of the set were sorted into an array in increasing order with regard to the angle that they and the starting point $S$ make with the x-axis (if two points have the same angle the point nearest to the previous one was put first). The algorithm was started, considering the first two points $A$ and $B$ of the array plus the starting one $S$ and the angle formed by these three points was found. If the orientation of 
these three points (considering them in same order) was not counter clockwise, we discarded $A$, otherwise we kept it in the Dante convex envelope. Next considering the successive points of the array, and keeping track of the recent three points (for example, for the second step considering points $A, B$ and $C$ ), the angle formed by them was found. At the same time if the orientation of these points was not counter clockwise, the middle one was discarded (for example, $B$ in the second step), otherwise it was kept in the Dante convex envelope. The algorithm ended when all the $N_{l^{-}} 1$ points of the array ended. This process could eventually return to the point at which it started, at which point the algorithm was completed. With the same procedure, the Montesanto convex envelope was estimated.

By estimating the two "catchment areas" it was possible to compare the geometrical (Figures 4 and 5), the socio-economic (Figure 6) and the accessibility characteristics (Figures 7 and 8). The catchment area of Dante station has an area of $1.75 \mathrm{kmq}, 99 \%$ more than the catchment area of Montesanto $(0.88 \mathrm{kmq})$. Furthermore, the equivalent circle for each basin (estimated in terms of equivalent area) was estimated, so it was estimated that the average radius of the Dante catchment area (that is 750 metres) is $42 \%$ larger than the Montesanto one (that is, 530 metres), as reported in Figure 5.

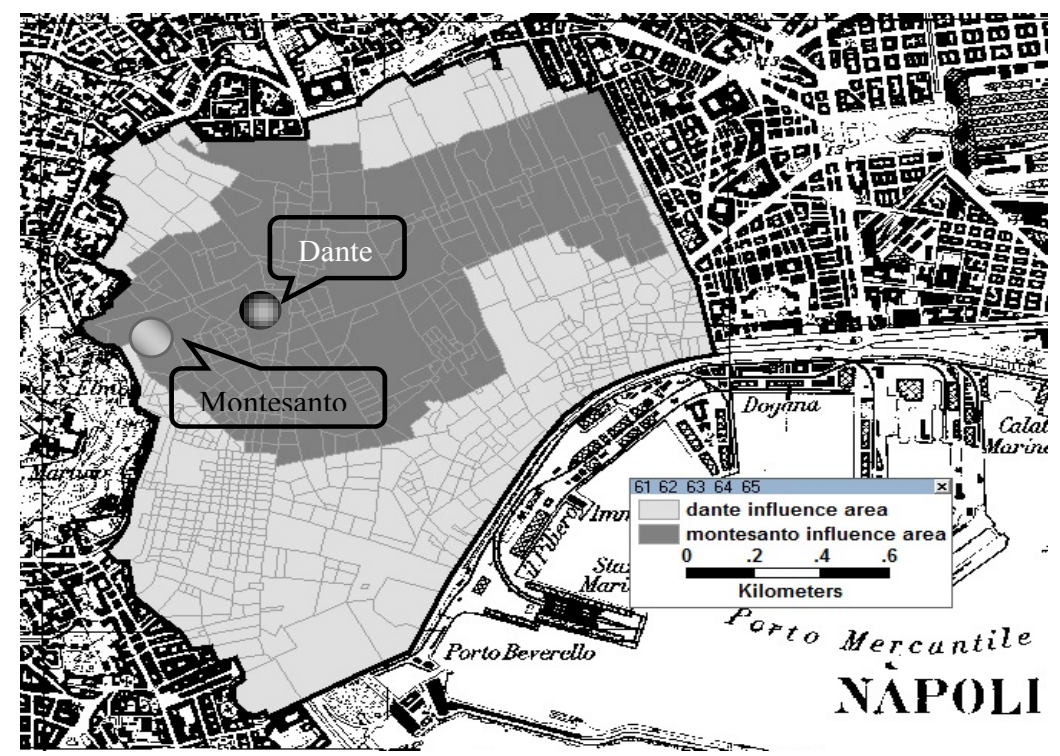

Figure 4: Dante and Montesanto catchment areas.

The area of the city, where the two stations are located, is characterized by a high population density and much activity (e.g. shops, offices and university buildings). For this reason, and considering that the catchment area of Dante is about double of the Montesanto one, the Dante station serves 120\% more of the population, $227 \%$ more employees and 183\% more firms (Figure 6). 


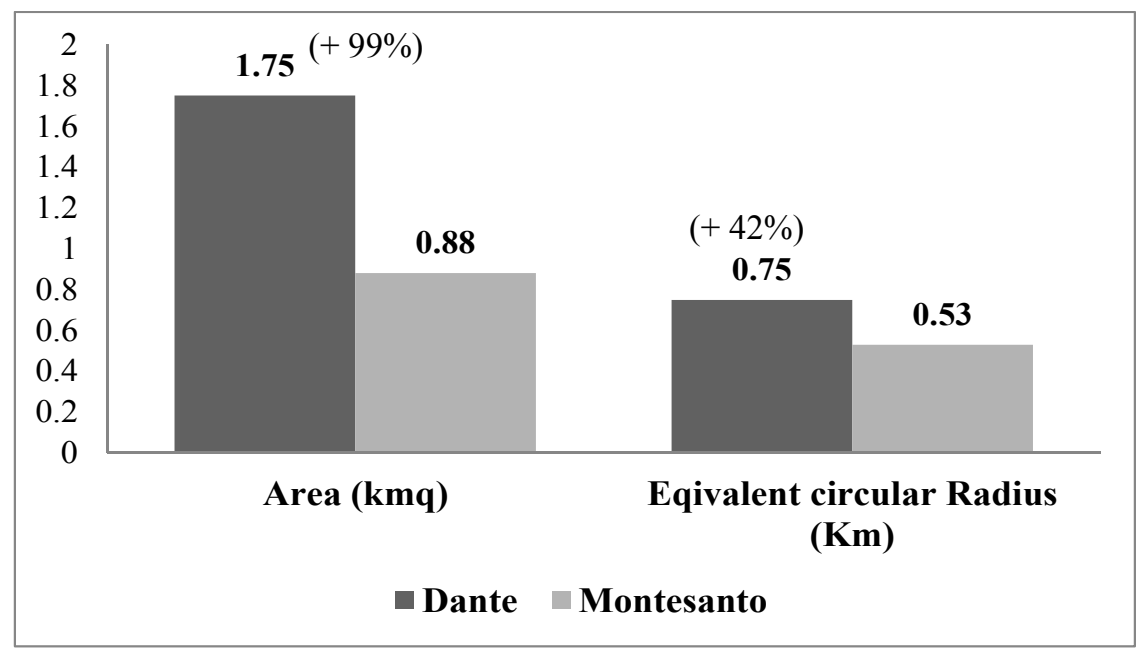

Figure 5: Geometric characteristics of Dante and Montesanto catchment areas.

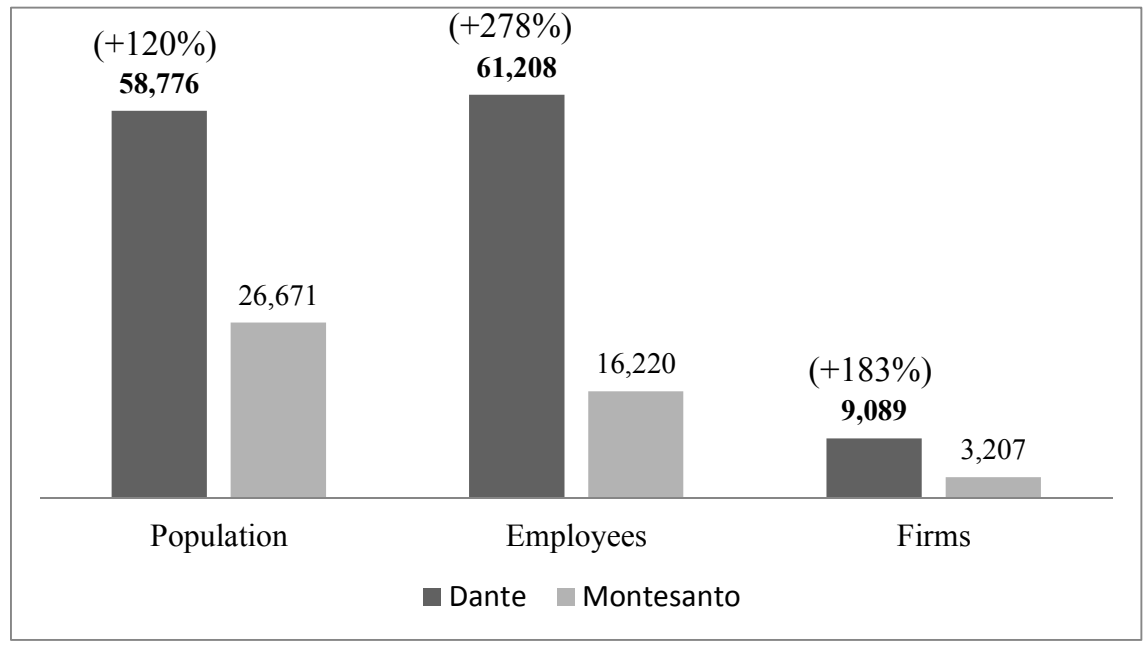

Figure 6: Socio-economic characteristics of catchment areas.

The catchment area of the two stations, has been divided into time sections (accessibility) with regard to the average walking time between the origin/destination and the stations (Figures 7 and 8). Using a transport network model implemented for the city of Naples (for details see [14-16]), it has been possible to estimate the walking distance on the minimum path that links the origin/destination declared by the users, with the station of interest. For each station, the $N_{1}$ and $N_{2}$ points have been divided into another 5 subsets that correspond to the 5 time sections identified: $0-5$ minutes; 5-10 minutes; 10-15 minutes; $>20$ minutes (e.g. $\left.N_{l[0-5]} ; N_{l[5-10]} ; N_{1[10-15]} ; N_{l[15-20]} ; N_{l[>20]}\right)$. Then, 
Graham's scan method was also used for each $N_{l[i-j]}$ and $N_{2[i-j]}$ sets to estimate the correspondent convex envelope.

Figures 9 and 10 show the number of people and employees living or being in the different convex envelopes (time sections). The estimation results show that the Dante station serves (within 10 minutes) $155 \%$ more of the population (Figure 9), 207\% more employees (Figure 10) and 130\% more firms.

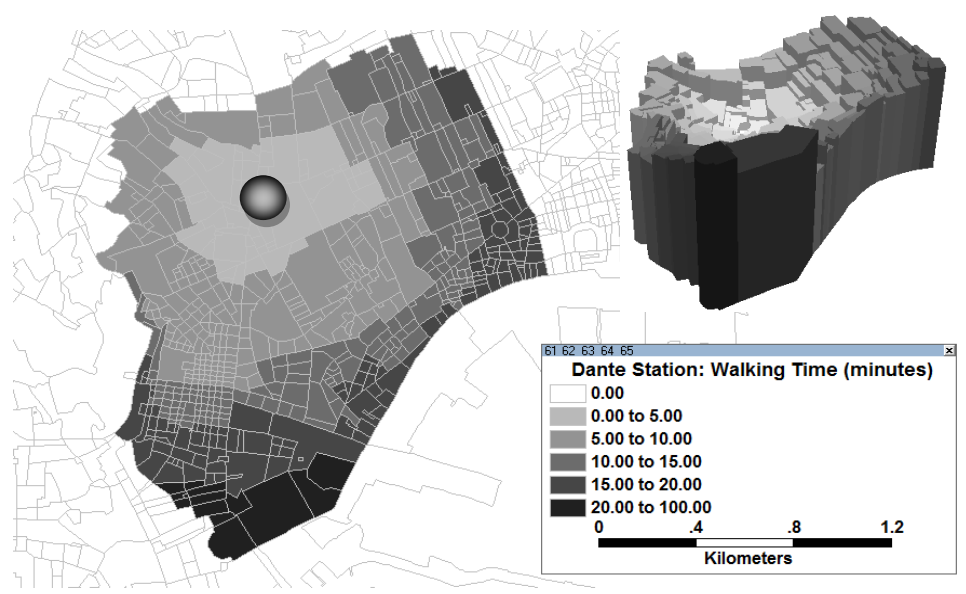

Figure 7: Dante station catchment area, walking isochronic map in 2D and 3D.

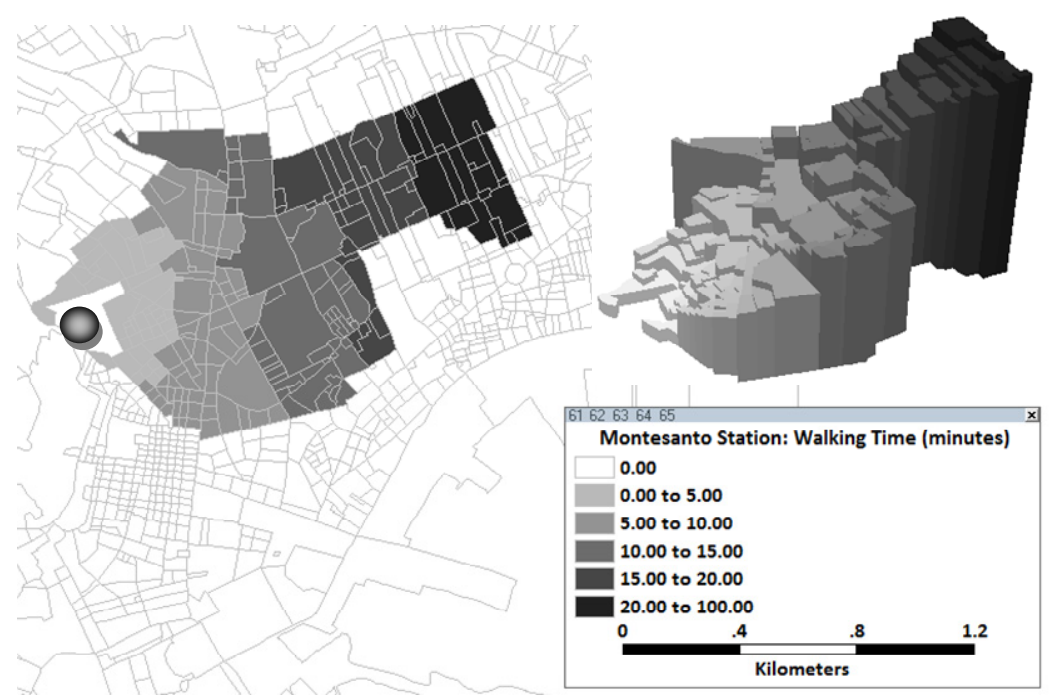

Figure 8: Montesanto station catchment area, walking isochronic map in 2D and $3 \mathrm{D}$. 


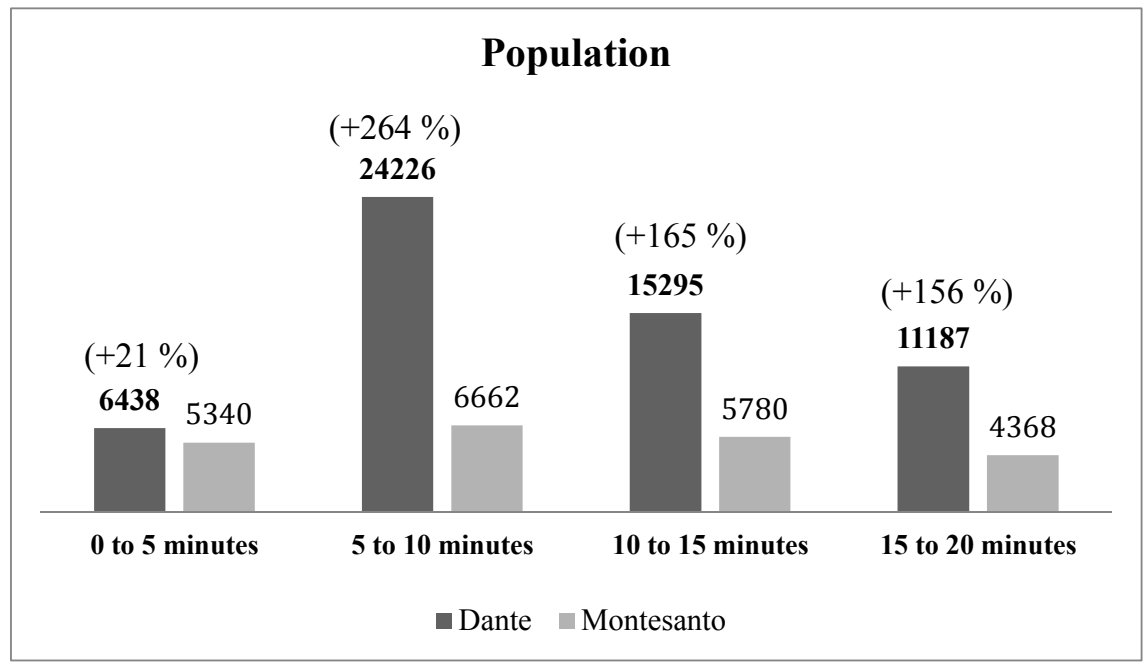

Figure 9: Population served for different time sections (isochrones).

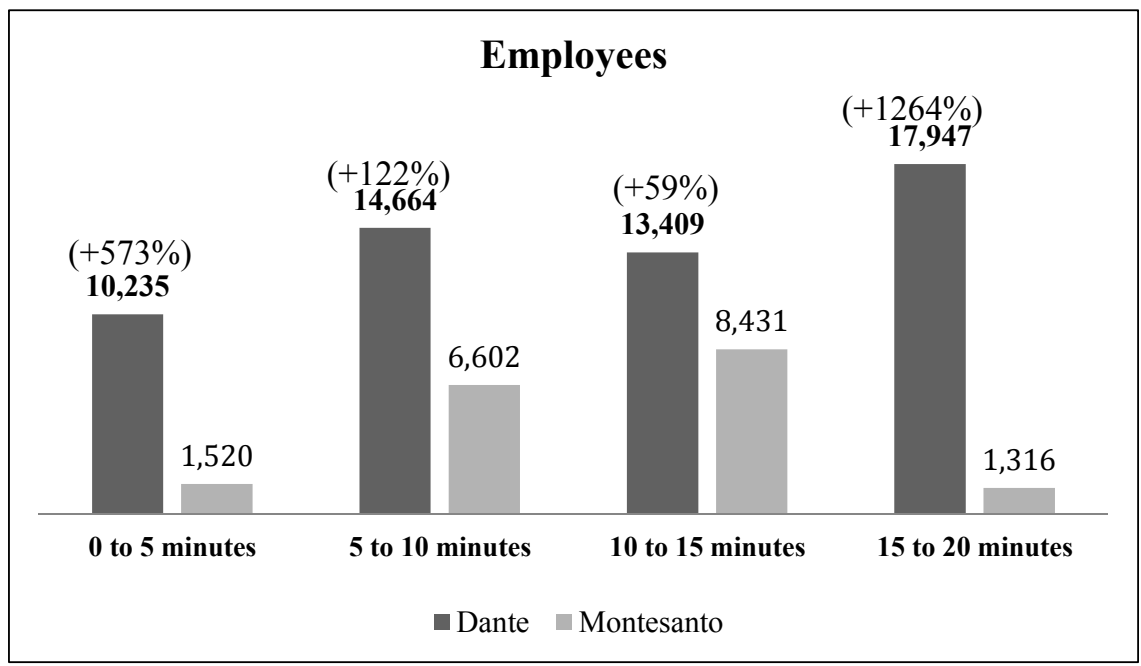

Figure 10: Employees served for different time sections (isochrones).

\section{Conclusion and research perspectives}

The aim of this paper was: (1) to estimate and compare the "catchment area" of traditional metro stations with high architectural quality ones; (2) to propose a transport application of Graham's scan algorithm for the estimation of the station catchment area. The originality of the experiment performed was that the two metro lines analysed connect homogeneous areas of the city. 
The results of Graham's scan algorithm application show that the "catchment area" of the high quality station is approximately $99 \%$ more than a traditional one. These results suggest that high architectural standards for railways stations should be considered as an explicit design variable in transportation planning (e.g. [17-19]). Starting from these results, the research perspectives will be:

- calibrate a demand model with explicit aesthetic quality attributes (starting with the results of $[14,20,21])$;

- estimate accessibility indicators (measures) considering the behavioral effect of architectural quality of transport terminal for travellers (e.g. [22, 23]);

- migrate the concept of aesthetic quality for passengers as well as for freight transport. A more pleasant, clean and environmentally friendly freight transport terminal is more sustainable for the welfare of the cities (e.g. ports in the city center that degrade the landscape and create pollution). From these considerations, both simulation models (e.g. [24-26]) and freight accessibility measures based on hedonic quality of the terminal will be calibrated (starting from the results from $[27,28]$ ).

\section{References}

[1] Kido, E.M., Aesthetic aspects of railway stations in Japan and Europe, as a part of context sensitive design for railways, Journal of the Eastern Asia Society for Transportation Studies, Vol. 6, pp. 4381-4396, 2005.

[2] Edwards, B., The Modern Station, London: E \& FN Spon, 1997.

[3] Cascetta, E., Cartenì, A., The hedonic value of railways terminals. A quantitative analysis of the impact of stations quality on travellers behaviour. Transportation Research Part A vol. 61, pp. 41-52, 2014. DOI:10.1016/j.tra.2013.12.008.

[4] Cascetta E., Cartenì, A., Carbone A., The quality in public transportation. The campania regional metro system (La progettazione quality-based nel trasporto pubblico locale, Il sistema di metropolitana regionale della Campania). Ingegneria Ferroviaria, 68 (3), pp. 241-261, 2013. ISSN: 0020-0956.

[5] Cascetta E., Cartenì, A., Henke I., Stations quality, aesthetics and attractiveness of rail transport: empirical evidence and mathematical models [Qualità delle stazioni, estetica e attrattività del trasporto ferroviario: evidenze empiriche e modelli matematici], Ingegneria Ferroviaria, 2014.

[6] Otto, S., Environmentally sensitive design of transportation facilities, Journal of Transportation Engineering 126(5), pp. 363-366, 2000.

[7] Holgate, A., Aesthetics of Built Form, Oxford University Press, New York, 1992.

[8] Transportation Research Board, A Handbook for Measuring Customer Satisfaction and Service Quality, TCRP Report 47, Washington DC: National Academy Press, 1999. 
[9] Transportation Research Board, Transit Capacity and Quality of Service Manual, TCRP Report 100, Washington DC: National Academy Press, 2003.

[10] Cascetta, E., Cartenì, A., A quality-based approach to public transportation planning: theory and a case study, International Journal of Sustainable Transportation, Taylor \& Francis, Vol. 8, Issue 1. pp. 84-106. 2014. DOI: 10.1080/15568318.2012.758532.

[11] The Daily Telegraph, http://www.telegraph.co.uk/travel/The-mostimpressive underground-railway-stations-in-Europe.html.

[12] CNN, http://edition.cnn.com/travel/europes-best-metro-stations/.

[13] Graham, R.L., An Efficient Algorithm for Determining the Convex Hull of a Finite Planar Set, Information Processing Letters 1, 132-133,1972.

[14] Bifulco, G.N., Cartenì, A. and Papola, A., An activity-based approach for complex travel behaviour modelling, European Transport Research Review, 2(4), pp. 209-221, 2010. DOI: 10.1007/s12544-010-0040-3.

[15] Cartenì, A., Updating demand vectors using traffic counts on congested networks: A real case application, WIT Transactions on the Built Environment 96, pp. 211-221, 2007. DOI: 10.2495/UT070211.

[16] Cartenì, A., Punzo, V., Travel time cost functions for urban roads: A case study in Italy, WIT Transactions on the Built Environment 96, pp. 233-243, 2007.

[17] Cascetta, E., Cartenì, A., Pagliara F., Montanino, M., A new look at planning and designing transportation systems as decision-making processes, Transport Policy, 2014.

[18] D'Acierno, L., Ciccarelli, R., Montella, B., Gallo, M., A multimodal multiuser approach for analysing pricing policies in urban contexts, Journal of Applied Sciences, 11(4), pp. 599-609, 2011.

[19] Gallo, M., D'Acierno, L., Montella, B., A multimodal approach to bus frequency design, WIT Transactions on the Built Environment, 116, pp. 193-204, 2011.

[20] de Luca, S., Cartenì, A., A multi-scale modelling architecture for estimating of transport mode choice induced by a new railway connection: The Salerno-University of Salerno-Mercato San Severino Route [Un'architettura modellistica multi-scala per la stima delle ripartizioni modali indotte da un nuovo collegamento ferroviario: il caso studio della tratta Salerno-Università di Salerno-Mercato San Severino], Ingegneria Ferroviaria, 68 (5), pp. 447-473, 2013.

[21] Cartenì, A., Campana S., Particulate Matter concentrations in a new section of a metro line: a case study in Italy, WIT Transactions on the Built Environment, 2014.

[22] Cascetta, E., Cartenì, A., Montanino, M., A New Measure of Accessibility Based On Perceived Opportunities, Procedia - Social and Behavioural Sciences, Volume 87, pp. 117-132, 2013. ISSN 1877-0428. DOI:10.1016/j.sbspro.2013.10.598. 
[23] de Luca, S., Modelling airport choice behaviour for direct flights, connecting flights and different travel plans, Journal of Transport Geography, 22, pp. 148-163, 2012.

[24] Cartenì, A., de Luca, S., Analysis and modeling of container handling equipment activities, European Transport - Trasporti Europei, (46), pp. 52-71, 2010.

[25] Cartenì, A., de Luca, S., Tactical and strategic planning for a container terminal: Modelling issues within a discrete event simulation approach, Simulation Modelling Practice and Theory, 21(1), pp. 123-145, 2012. DOI: 10.1016/j.simpat.2011.10.005.

[26] de Luca, S., Cantarella, G.E., Cartenì, A., A macroscopic model of a container terminal based on diachronic networks, Operations Research/ Computer Science Interfaces Series, 46, pp. 285-310, 2009.

[27] Cartenì, A., Russo, F., A distribution regional freight demand model, Advances in Transport, 16, pp. 275-285, 2004. ISSN: 1462608X.

[28] Cartenì, A., Accessibility indicators for freight transport terminals, Arabian Journal for Science and Engineering, 2014. 